\title{
MICROMODELS FOR THE IN-PLANE FAILURE ANALYSIS OF MASONRY WALLS WITH FRICTION: LIMIT ANALYSIS AND DEM-FEM/DEM APPROACHES
}

\author{
M. Pepe ${ }^{1}$, M. Pingaro ${ }^{1}$, E. Reccia ${ }^{2}$, and P. Trovalusci ${ }^{1}$ \\ ${ }^{1}$ Department of Structural and Geotechnical Engineering, Sapienza University of Rome \\ Via Antonio Gramsci 53, 00197, Rome, Italy \\ e-mail: \{marco.pepe,marco.pingaro,patrizia.trovalusci\}@uniroma1.it \\ ${ }^{2}$ Department of Civil and Environmental Engineering and Architecture, University of Cagliari \\ Via Marengo 2, 09123, Cagliari, Italy \\ e-mail: emanuele.reccia@unica.it
}

Keywords: Masonry, Rigid Blocks, Limit Analysis, Distinct Element Method

\begin{abstract}
Despite its complexity, the accurate structural modelling of masonry still represents an active field of research, due to several practical applications in civil engineering, with special reference to the preservation and restoration of cultural heritage.

In this work a comparison of different models and techniques for the assessment of the mechanical behaviour of two-dimensional block masonry walls subjected to the static action of in-plane loads is presented.

Panels are characterized by different height-to-width ratio as well as various masonry textures. Brick-block masonry, perceived as a jointed assembly of prismatic particles in dry contact, is modelled as a discrete system of rigid blocks interacting through contact surfaces unable to carry tension and resistant to sliding by friction, modelled as zero thickness elasto-plastic Mohr-Coulomb interfaces.

Different approaches and numerical models are considered: Limit Analysis (LA), Discrete Element Model (DEM) and Finite Elements/Discrete Element Model (FEM/DEM). Limit Analysis is able to provide fast and reliable results in term of collapse multiplier and relative kinematism. Here a standard Limit Analysis is adopted via an own made procedure based on Linear Mathematical Programming, taking into account friction at interfaces.
\end{abstract}




\section{INTRODUCTION}

Masonry is a composite and heterogeneous material obtained by assembling natural or artificial blocks by means of mortar layers or dry joints and it is one of the more common structural materials adopted for centuries for ordinary or monumental constructions. The investigation of its mechanical behaviour plays a fundamental role in view of the protection and conservation of architectures of historical and archaeological interest. However, to deal with the structural response of historical masonry structure is a complex task. In the last decades a large variety of numerical models and approaches have been proposed in literature, but no one can be applied in a general manner regardless the constructive typology. The selection of the most appropriate modelling strategy is indeed strictly related with the nature of the object to analyse.

Depending on the adopted model for analysis it is possible introduce three distinct categories: micro-mechanical, macro-mechanical models and multiscale models. The choice of a micromodeling strategy involves a distinct representation of masonry constituents(units, mortar and unit/mortar interface) which properties are obtained from experimental test on small masonry specimen. A micromechanical model is suitable for a very detailed response [22, 23, 27, 3, 34], but this approach has a limit represented by the great computational effort due to the high number of degree of freedom connected to each unit and joint in case of real masonry structures, characterized by considerable number of units. Macroscopic models use phenomenological constitutive laws for constituents, including also some inner variables for damage and friction, and masonry is considered as a homogenized continuum. Its parameters are derived by means of experimental tests on small masonry specimen or directly on the single constituents. Macromechanical models are characterized by high computational efficiency since they not provide an accurate description of the internal structure of masonry material [13, 10, 21].

Multiscale, i.e. micro-macro, continuum models represent a very promising approach for the analysis of masonry structures since they can accurately retain memory of the the mechanical and geometrical properties of the material (microstructure) together with the capability to contain the computational effort compared to a fully micromechanical model[25, 36, 20, 33]. These models are often derived by considering two material scales: a microscale where, after deducing the mechanical properties of the components through experimental tests, a material representative volume element (RVE) is defined and a macroscale structural level, where a homogeneous continuum is obtained by performing a homogenization procedure based on the solution of boundary conditions problems for the RVE [2, 1, 16, 17, 33, 30, 29]. Other multiscale strategies have been proposed that exploit different homogenization techniques exploiting the so-called Cauchy rule, and its, generalizations [9] that allowed the derivation of generalized continua able to properly represent scale effects, that in masonry materials are prominent [25, 35, 28, 15, 19].

In this work the attention is mainly focused on the category of micro-models particularly focusing on Limit Analysis, which represents a very effective tool to estimate the collapse load and collapse mechanism for masonry structures [5, 31, 11]. A validation of the proposed model is provided, via suitable comparisons with the results provided in [7, 8], here regarded as a benchmark, where two micro-mechanical models that finely describe the microstructure, based on the discrete element method (DEM) and on a combined finite/discrete element method (FEM/DEM), have been adopted to the evaluation of the failure in-plane behaviour of masonry panels with several hight-to-width ratio and different arrangements of blocks. The comparison of the numerical results has shown the efficacy of the limit analysis for the in-plane failure analysis of masonry walls. 


\section{ADOPTED MICROMODELS}

\subsection{Rigid block model for limit analysis}

The first selected model adopted is framed within the Limit Analysis (LA) theory in the presence on non-associative laws, due to the necessity to take into account friction [32, 4]. This model considers a system of $n$ rigid blocks and $m$ joints. The blocks can translate and rotate about the edges of the contact surfaces (hinging) as well as sliding along the joints.

Let introduce $\boldsymbol{e}=\left\{e_{1}, e_{2}, e_{3}\right\}^{T}$ the orthonormal basis in the three-dimensional space. We consider the two blocks in Figure 11. Loads are applied to the centroid of each rigid block $i-$ th: static 'dead' loads are collected in vector $\boldsymbol{f}_{0}^{i}=\left\{f_{01}^{i}, f_{02}^{i}, m_{03}^{i}\right\}^{T}$, live loads are collected in the vector $\boldsymbol{f}_{L}^{i}=\left\{f_{L 1}^{i}, f_{L 2}^{i}, m_{L 3}^{i}\right\}^{T}$. For the whole structure it results $\boldsymbol{f}_{0}=\left\{\boldsymbol{f}_{0}^{i}\right\}$ and $\boldsymbol{f}_{L}=\left\{\boldsymbol{f}_{L}^{i}\right\}$, with $i=1, \ldots, n$. The vector of the load over the whole system is $\boldsymbol{f}=\boldsymbol{f}_{0}+\alpha \boldsymbol{f}_{L}$, where live loads are proportional to the dead loads through a non-negative coefficient, $\alpha$, called collapse multiplier. Let $\boldsymbol{u}^{i}=\left\{u_{1}^{i}, u_{2}^{i}, \theta_{3}^{i}\right\}$ denote the vector of generalized displacement of the centroid of each $i$-th block. The vector $\boldsymbol{u}=\left\{\boldsymbol{u}^{i}\right\}$, with $i=1, \ldots, n$, collects the displacement for the whole structure which correspond in a virtual work sense to loads $f$.

The static variables are the internal forces acting at each $j$-th contact surface between blocks, that is the normal force $N^{j}$, the shear force $T^{j}$ and the moment $M^{j}$. For each joint they are collected in vector $\boldsymbol{\sigma}^{j}=\left\{N^{j}, T^{j}, M^{j}\right\}^{T}$. The vector $\boldsymbol{\sigma}=\left\{\sigma^{j}\right\}$, with $j=1, \ldots, m$, refers to the whole structure.

The kinematic variables, or generalized strain, are the relative displacement rates at joints, that is normal displacement $\xi^{j}$, tangential displacement $\gamma^{j}$ and rotation $\chi^{j}$. For each joint $j=1, \ldots, m$ they are collected in the vector $\varepsilon^{j}=\left\{\xi^{j}, \gamma^{j}, \chi^{j}\right\}^{T}$. The vector $\varepsilon=\left\{\varepsilon^{j}\right\}$ refers to the whole structure and corresponds in a virtual work sense to the vector of static variables $\sigma$. Removing
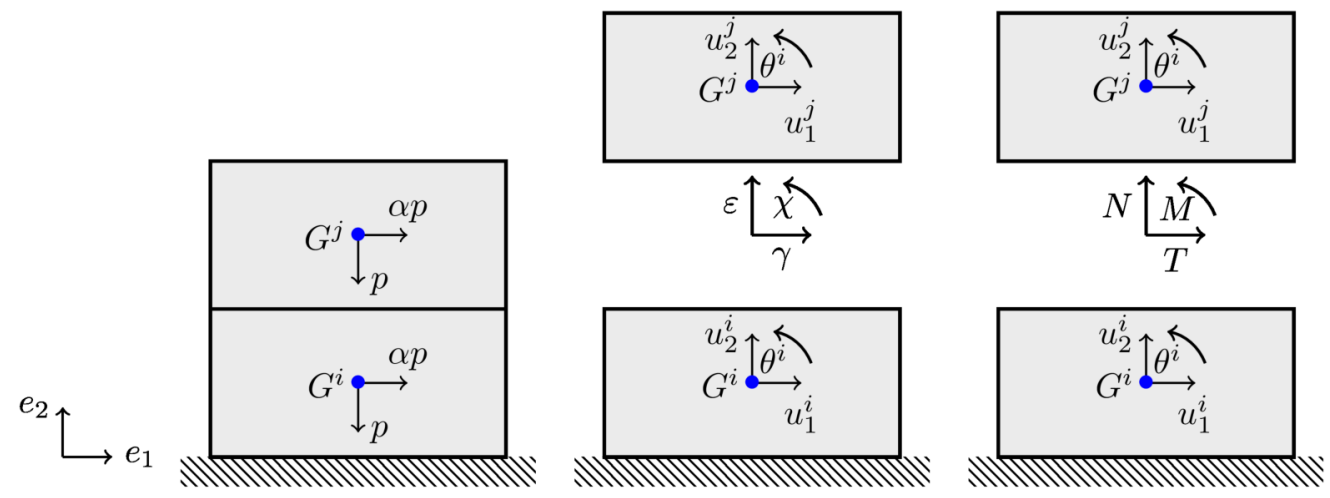

Figure 1:

the hypothesis of joint deformability, which implies some uncertainties about the determination of the stiffness material parameters, masonry is described as a system of rigid blocks directly interacting through contact surfaces unable to carry tension and resistant to sliding by friction. The set of equations for the model are represented by:

$$
\begin{aligned}
& \boldsymbol{\varepsilon}=\boldsymbol{B} \boldsymbol{u}, \\
& \boldsymbol{B}^{T} \boldsymbol{\sigma}+\boldsymbol{f}=\mathbf{0}, \\
& \boldsymbol{y}=\boldsymbol{N}^{T} \boldsymbol{\sigma} \leq \mathbf{0}, \\
& \boldsymbol{\varepsilon}=\boldsymbol{M} \boldsymbol{\lambda},
\end{aligned}
$$




$$
\begin{aligned}
\lambda^{T} \boldsymbol{y} & =0 \\
\boldsymbol{f}_{L}^{T} \boldsymbol{u} & =1
\end{aligned}
$$

Where Equation 1 represents the kinematic compatibility for the whole system of interfaces and blocks, Equation 2 defines the equilibrium for the whole structure, equation 3 is the generalized yield domain of the system, equation 4 represents the flow rule which express the vector $\varepsilon$ as a linear combination with non-negative coefficients $\lambda$, called inelastic multiplier, Equation 5 is the complementarity condition which defines the plastic behaviour of contact surface. Moreover, the collapse mechanism must be characterized by a non-negative work of the live loads, defined by Equation 6 .

Within the framework of the holonomic perfect plasticity, the same relations govern the problem of a non-standard rigid-plastic discrete materials. Resorting this formal analogy, the collapse load for a masonry structure, under the hypothesis of proportional load with the factor $\alpha>0$, can be determined. In [5], after some algebra the authors obtained the following non-linear and non-convex programming problem (NLNCP)

$$
\begin{aligned}
\alpha_{c}=\min \{\alpha\} \quad & \text { subjected to } \\
& \left(\boldsymbol{A} \boldsymbol{M}_{1}-\boldsymbol{M}_{2}\right) \boldsymbol{\lambda}=\mathbf{0} \\
& \left(\boldsymbol{A}_{0} \boldsymbol{N}_{1}\right)^{T}\left(\boldsymbol{f}_{0}+\alpha \boldsymbol{f}_{L}\right)+\left[\boldsymbol{N}_{2}^{T}-\left(\boldsymbol{A} \boldsymbol{N}_{1}\right)^{T}\right] \boldsymbol{\sigma}_{2} \leq \mathbf{0} \\
& \boldsymbol{\lambda}^{T}\left(\boldsymbol{A}_{0} \boldsymbol{M}_{1}\right)^{T} \boldsymbol{f}_{L}-1=0 \\
& \boldsymbol{\lambda}^{T}\left\{\left(\boldsymbol{f}_{0}+\alpha \boldsymbol{f}_{L}\right)+\left[\boldsymbol{N}_{2}^{T}-\left(\boldsymbol{A} \boldsymbol{N}_{1}\right)^{T}\right] \boldsymbol{\sigma}_{2}\right\}=0,
\end{aligned}
$$

with the unknowns $\alpha, \boldsymbol{\sigma}_{2}, \boldsymbol{\lambda}$ and the bounds $\boldsymbol{\lambda} \geq 0$ and $\alpha \geq 0$. The authors developed a home-made code, ALMA (Analisi Limite Murature Attritive) to deal with the NLNCP. However, the problem of Limit Analysis of structures with frictional interfaces (non-standard LA) could become numerically very difficult to be solved, as it corresponds to a NLNCP for which the solution does not exist and when it exists it could be a local minimum instead of the global one [14].

On the other end, due to the presence of non-associative flow rules, the Drucker stability postulate no longer holds and the solution in terms of contact actions and collapse load factor loses its uniqueness. Moreover, bi-dimensional or three-dimensional real structures, characterized by many degrees of freedom, increase the computational complexity of the problem.

In [5] the authors proposed a two-step procedure to solve the problem: in the first step a linear programming problem (LP), obtained by replacing friction with dilatancy, is solved; in the second step, the NLNCP solution is approached using, as initial guess for the unknowns of the problem, the solution of the first step. In this way the analysis easily converges to the optimal point.

Nevertheless, approaching the non-standard problem could be a hard and difficult issue. Many authors proposed several techniques to deal with it, mainly based on the linearisation of the problem. From LA theory it is well known that if normality rule holds, i.e. the vector of inelastic strain results normal to the yield surface, the static and kinematic theorems of limit analysis could be formulated in a linear programming context, resulting in two dual problems, which lead to a unique solution.

To overcome some computational limits of the original code $A L M A$, mainly related to the number of blocks and interfaces involved into analysis, a new version of the code, ALMA 2.0, was implemented using $M A T L A B^{\circledR}$ for linear optimization and a Python ${ }^{T M}$ interface for pre and post processing operations. 
Following the approach in [5], results of this work refers to the kinematic approach which provides the collapse multiplier and the corresponding mechanism. Friction is considered in term of dilatancy. The kinematic problem is defined as

$$
\begin{aligned}
\alpha_{c}=\min \left\{-\boldsymbol{\lambda}^{T}\left(\boldsymbol{A}_{0} \boldsymbol{N}_{1}\right)^{T} \boldsymbol{f}_{0}\right\} \quad & \text { subjected to } \\
& \left(\boldsymbol{A} \boldsymbol{N}_{1}-\boldsymbol{N}_{2}\right) \boldsymbol{\lambda}=\mathbf{0} \\
& \boldsymbol{\lambda}^{T}\left(\boldsymbol{A}_{0} \boldsymbol{N}_{1}\right)^{T} \boldsymbol{f}_{L}-1=0,
\end{aligned}
$$

with the bounds on the unknowns $\boldsymbol{\lambda} \geq \mathbf{0}$.

\subsection{DEM and FEM/DEM}

In order to validate the proposed model, LA results in terms of collapse load and mechanism are compared to the results of a second model obtained with the models adopted in [7, 8], here considered as a benchmark. In the referred works, two micro-mechanical models have been proposed for the the in-plane failure analysis of masonry walls: a discrete element method (DEM) and a combined finite/discrete element method (FEM/DEM). Both these models fall within the field of discrete or distinct element methods, which have been proved to be particularly suitable for the study of masonry structures [18, 33].

DEM model is based on the original numerical method formulated by [12], and recently developed by [6]. The model is based on the assumption of rigid block and mortar joints modelled as zero thickness elastic-plastic interfaces, adopting a Mohr-Coulomb yield criterion. Masonry is seen as a system of rigid blocks, whose interactions are represented by forces and moments depending on their relative displacements and rotations.

FEM/DEM method is a combination of discrete elements, originally formulated by [26], and developed by [24], it consists in a discrete element method in which the individual elements are meshed into finite elements, adopting a triangular discretization of the domain with embedded crack elements that activate whenever the peak strength is reached.

The method, initially developed in the field of geo-mechanics, has been adopted to study the behaviour of historical masonry Differently from the DEM described above, blocks can be assumed to behave as rigid or elastic bodies. Mortar joints might be idealized as elastic or elastic-plastic zero-thickness Mohr-Coulomb interfaces. Blocks are modelled by means of finite elements while interfaces are modelled as discrete elements.

\section{NUMERICAL RESULTS}

Limit analysis is compared with non-linear incremental analysis of the panels performed by means of DEM and FEM/DEM models. Attention is focused on the mechanisms of collapse and on ultimate load multipliers, $\alpha$, obtained using the different micromechanical approaches. Results refer to three different based supported panels with different dimensions and ratio $H / L$. The panel base length $L$ is assumed equal to $1140 \mathrm{~mm}$, whereas height $H$ is assumed equal to $L / 2$ (Case 1 ), $L$ (Case 2) and $2 L$ (Case 3). Brick sizes are characterized by length $b$ and height $a$. The panel thickness is setting to $t=120 \mathrm{~mm}$. Negligible cohesion $c$ is considered for representing dry joints, whereas a friction ratio $\tan \phi=0.6$ is assumed, corresponding to a friction angle of about $30^{\circ}$. Two different blocks arrangement are modelled: "running bond" pattern (RB) with $b=240 \mathrm{~mm}$ and $a=60 \mathrm{~mm}(b / a=4)$ and "head bond" pattern (HB) with $b=120 \mathrm{~mm}$ and $a=60 \mathrm{~mm}(b / a=2)$. A fictitious mortar elastic modulus $E^{M}=1 \mathrm{GPa}$ is assumed for representing dry joints elastic deformability. Each panel is subject to its self-weight and to a horizontal increasing force statically equivalent to a lateral acceleration. 


\begin{tabular}{cccccc}
\hline Case & $\mathrm{H} / \mathrm{L}$ & $\mathrm{b} / \mathrm{a}$ & $\alpha_{F E M / D E M}$ & $\alpha_{D E M}$ & $\alpha_{L A}$ \\
\hline \hline & & & & & \\
1 & 0.5 & $4 / 1$ & 0.500 & 0.570 & 0.600 \\
1 & 0.5 & $2 / 1$ & 0.410 & 0.390 & 0.500 \\
\hline 2 & 1.0 & $4 / 1$ & 0.380 & 0.390 & 0.600 \\
2 & 1.0 & $2 / 1$ & 0.320 & 0.310 & 0.435 \\
\hline 3 & 2.0 & $4 / 1$ & 0.240 & 0.330 & 0.427 \\
3 & 2.0 & $2 / 1$ & 0.220 & 0.310 & 0.360 \\
\hline
\end{tabular}

Table 1: Collapse multiplier $\alpha$ for different cases and approach

In Table 1 the collapse multiplier $\alpha$ obtained using FEM/DEM, DEM and LA, for each case considered, is reported.

Figure 2, Figure 3 and Figure 4 show the collapse mechanisms obtained by LA (c) compared with DEM (a) and FEM/DEM (b) for the three cases of study, considering running bond (upper line) and head bond (lower line) textures. Two possible mechanisms of collapse may occur: sliding or overturning, mainly depending on height-to-length ratio $\mathrm{H} / \mathrm{L}$ of the panel but related also to the arrangement of blocks.
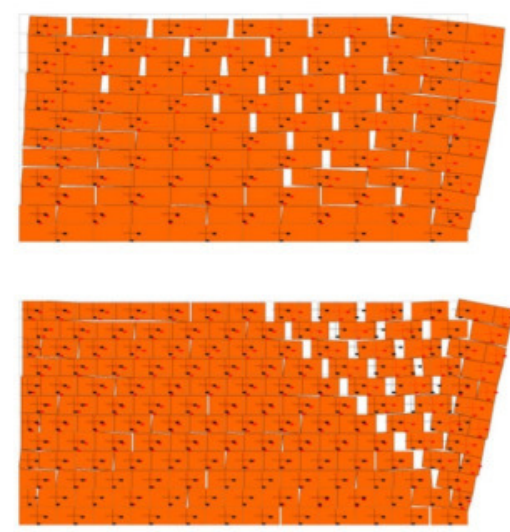

(a) DEM
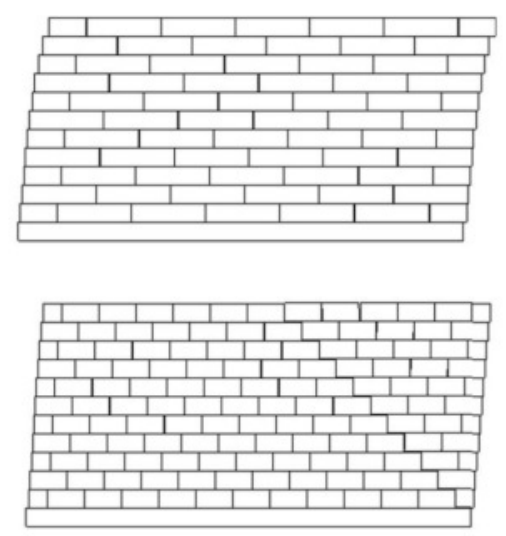

(b) FEM/DEM
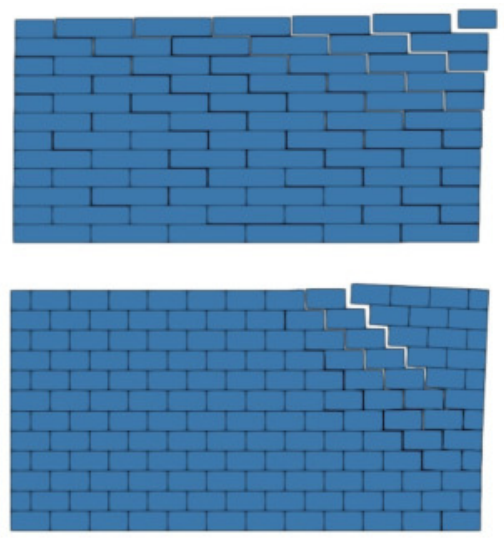

(c) LA

Figure 2: Case 1: Collapse mechanism obtained using FEM/DEM, DEM and LA in case of RB (upper line) and HB (bottom line)

The results provided by LA are in a good agreement with the ones provided by DEM and FEM/DEM. In slender panels (ratio $H / L>1$ ) collapse occur with prevalent global overturning mechanisms, while panels with a ratio $H / L<1$ exhibit a prevalent sliding mechanism; cracks pattern provided by AL are very similar to the one of DEM and FEM/DEM. However it must be noticed that, while in the first case overturning mechanism occurs both for RB and $\mathrm{HB}$ textures, in the latter case a pure sliding mechanism is activated in case of RB while in case of HB the upper part of the panel exhibits rotations. This phenomenon is more evident in the case of square panel (ratio $H / L=1$ ), for which the mechanism can be either sliding that overturning in relation to the texture considered. This results show that the global collapse mechanisms strongly depend depend on local mechanisms, that are related to the geometry of the microstructure.

Figure 5, Figure 6 and Figure 7 provide the values of the collapse multiplier obtained by the 

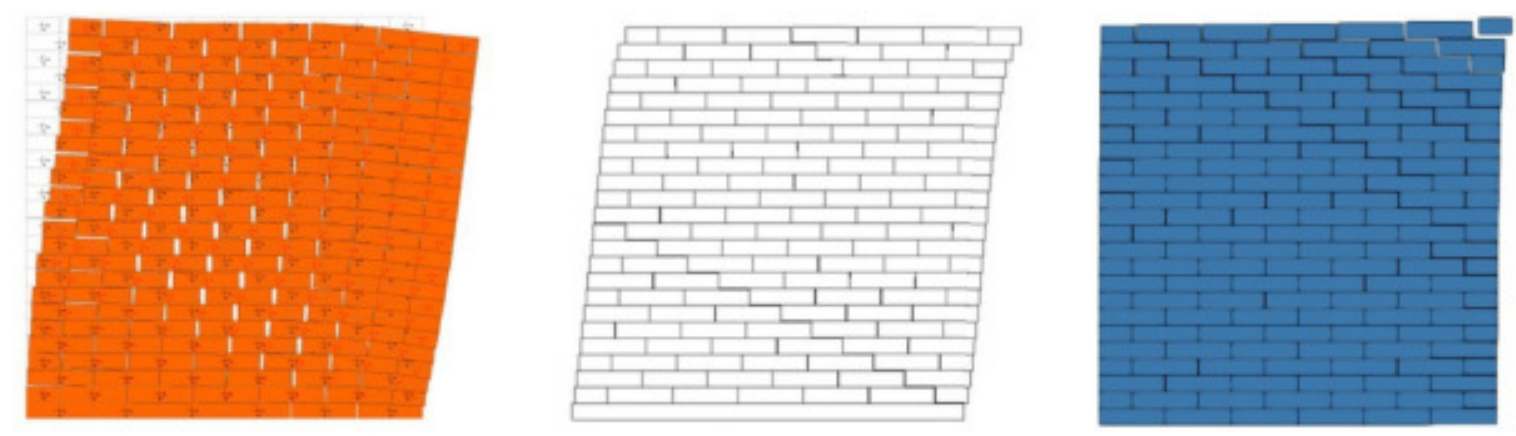

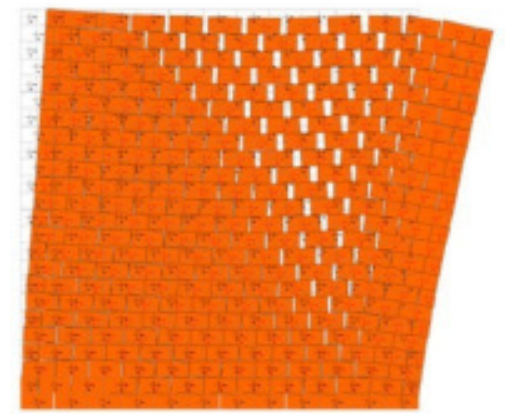

(a) DEM

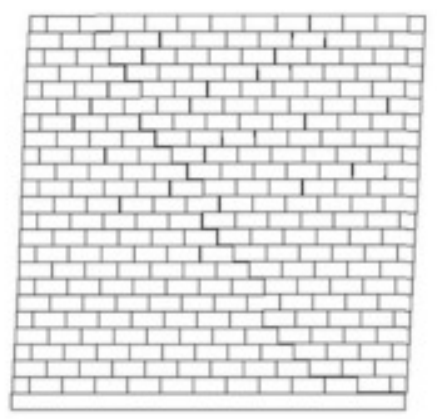

(b) FEM/DEM

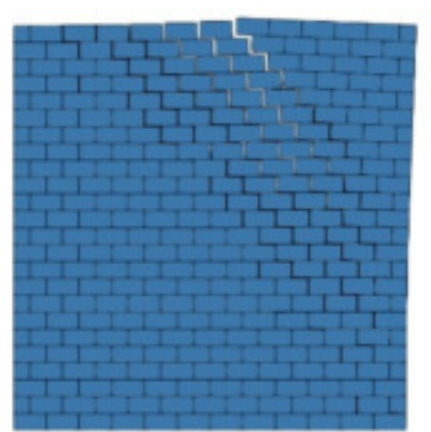

(c) LA

Figure 3: Case 2: Collapse mechanism obtained using FEM/DEM, DEM and LA in case of RB (upper line) and HB (bottom line)

three models: it is possible to notice that multipliers obtained by AL are comparable with respect to the other 2 models, even if they are little higher. It could be influenced by the dilatant behaviour hypothesis of the model. In Table 1 all the results are summarized.

\section{FINAL REMARKS}

The comparison of results show a good agreement between the different modelling techniques. In terms of collapse multiplier $\alpha$, the difference is more accentuate for the square panel, Case 2 $(H / L=1)$, as reported in Figure 6. Indeed, it is well known from literature how it represents a limit case between sliding or hinging mechanism. In particular with a LA approach, especially for HB pattern, the result seems to be influenced by the dilatant behaviour while results obtained using FEM/DEM and DEM are little smaller than the friction angle. On the contrary, the value of $\alpha$ for Case 1 and Case 3 are characterized by little difference between FEM/DEM, DEM and LA analysis, as reported in Figure 5 and Figure 7.

Referring to collapse mechanisms, results obtained using LA approach are in good agreement with those obtained with FEM/DEM and DEM analysis. In particular considering Case 1 and Case 2, for HB pattern the mechanism is mainly of sliding. Other cases and patterns exhibit an hinging mechanism of collapse.

A consideration about the use of the different techniques to model the structural response of masonry panels points out some advantages of LA approach. It may be a useful and reliable tool for the analysis of in-plane failure of masonry walls and to assess the collapse multiplier. Moreover, it is possible to take into account the real texture of masonry walls, describing accurately the real cracks pattern that may develop and the potential mechanisms of collapse, as shown by the comparison with the results obtained by means of discrete models. It also 


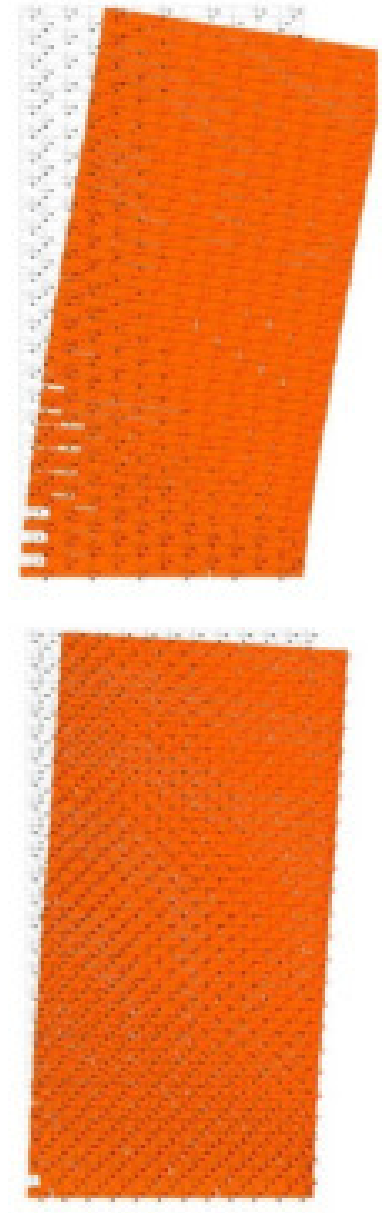

(a) DEM
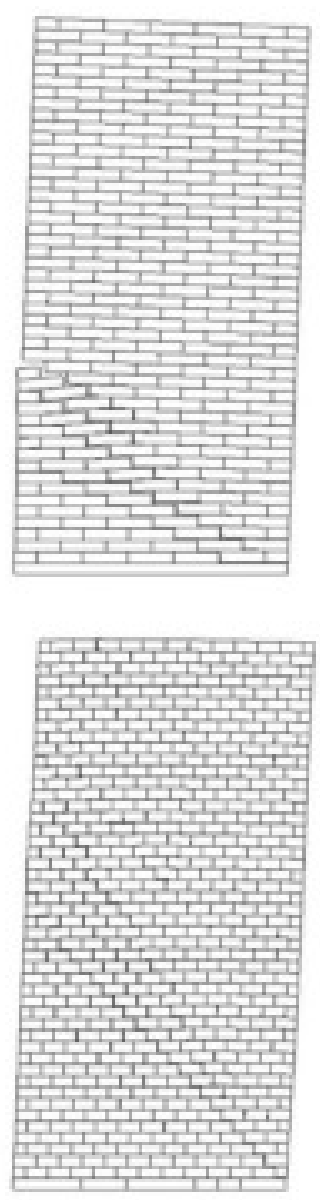

(b) FEM/DEM
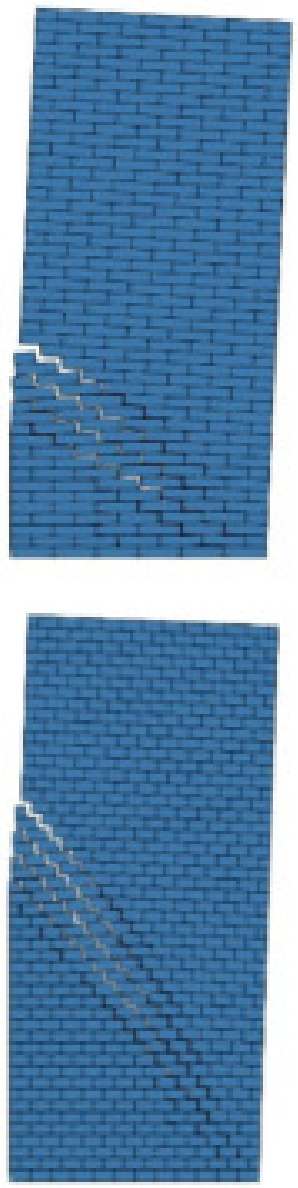

(c) LA

Figure 4: Case 3: Collapse mechanism obtained using FEM/DEM, DEM and LA in case of RB (upper line) and HB (bottom line)

requires less computational effort respect to FEM/DEM and DEM approach, which could represent a critical issue especially for structure with large degree of freedom. Another advantage of LA concerns the limited number of mechanical parameter to introduce into analysis. Indeed, unlike FEM/DEM and DEM which require more mechanical information, using LA the only parameter to set is the angle of friction.

Next step of the research will be focused on the analysis of more complex geometries, also including a linearised procedure to take into account pure shear and crushing of the blocks. The study about how settlements influenced the structural response is also an ongoing research.

\section{Acknowledgment}

This research was supported by Italian Ministry of University and Research: PRIN 2015, project 2015JW9NJT (B86J16002300001); PRIN 2017 (B88D19001130001); Sapienza Research Grants 'Progetti Medi' 2017 (B83C17001440005).

Dr. Reccia fully acknowledges the research project funded by P.O.R. SARDEGNA F.S.E. 20142020 - Axis III Education and Training, Thematic Objective: 10, Specific Objective: 10.5, Action of the Partnership Agreement: 10.5.12, Call for Funding of Research Projects - Year 


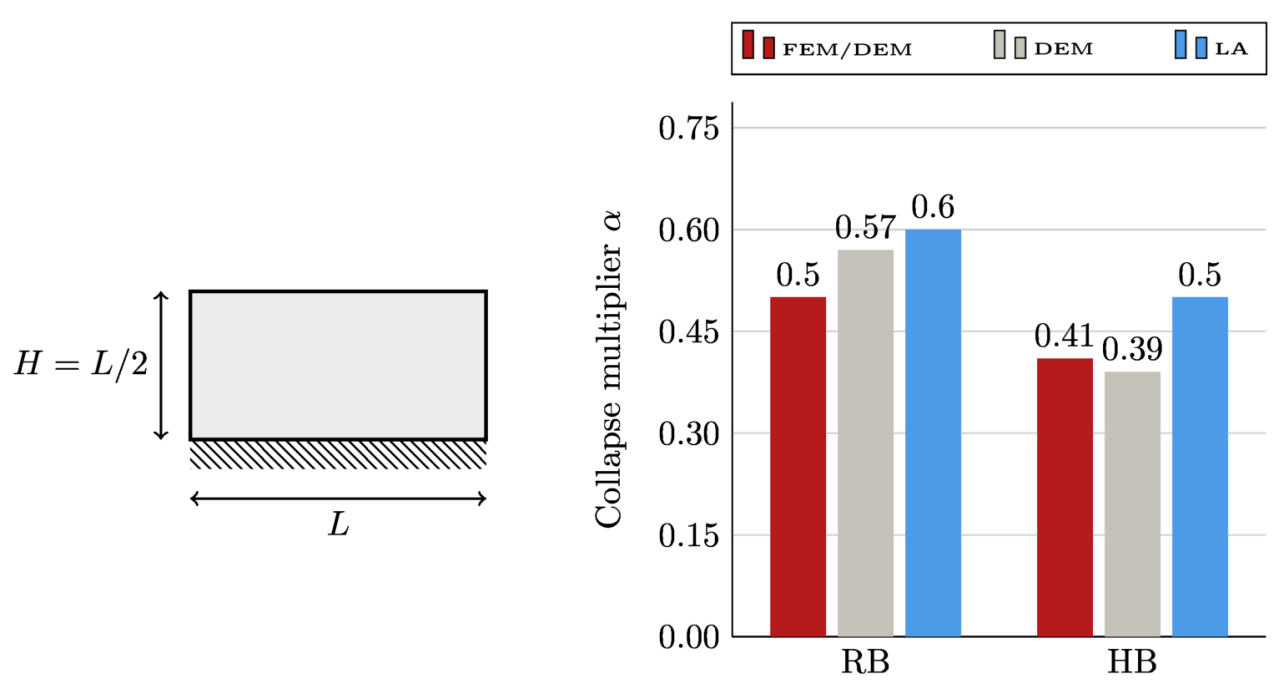

Figure 5: Case 1: Collapse multiplier for the analysed three approaches in the case $b / a=4 / 1(\mathrm{RB})$ and $b / a=2 / 1$ (HB)

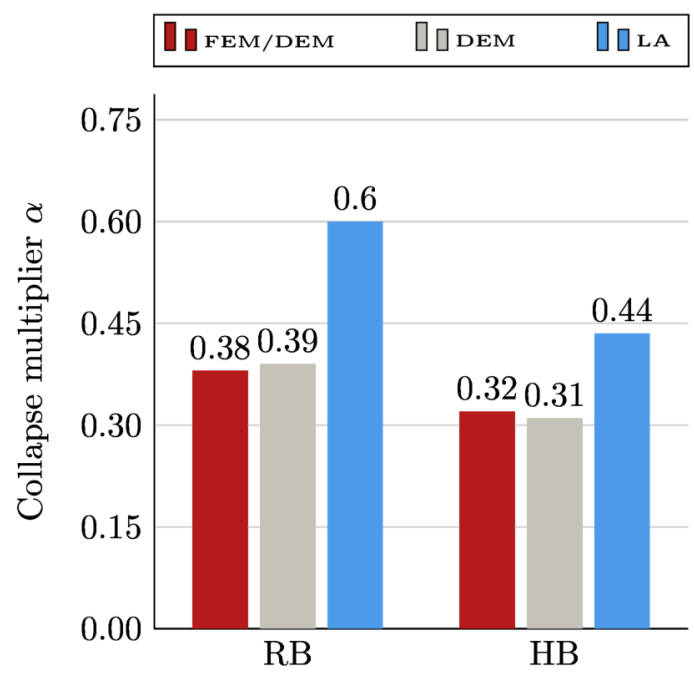

Figure 6: Case 2: Collapse multiplier for the analysed three approaches in the case $b / a=4 / 1(\mathrm{RB})$ and $b / a=2 / 1$ (HB)

2017.

\section{REFERENCES}

[1] D. Addessi, M. De Bellis, and E. Sacco. A micromechanical approach for the cosserat modeling of composites. Meccanica, 51(3):569-592, 2016.

[2] D. Addessi, E. Sacco, and P. Di Re. Multi-scale analysis of masonry structures. In Proceedings of the International Masonry Society Conferences, volume 0, pages 307-323, 2018. 

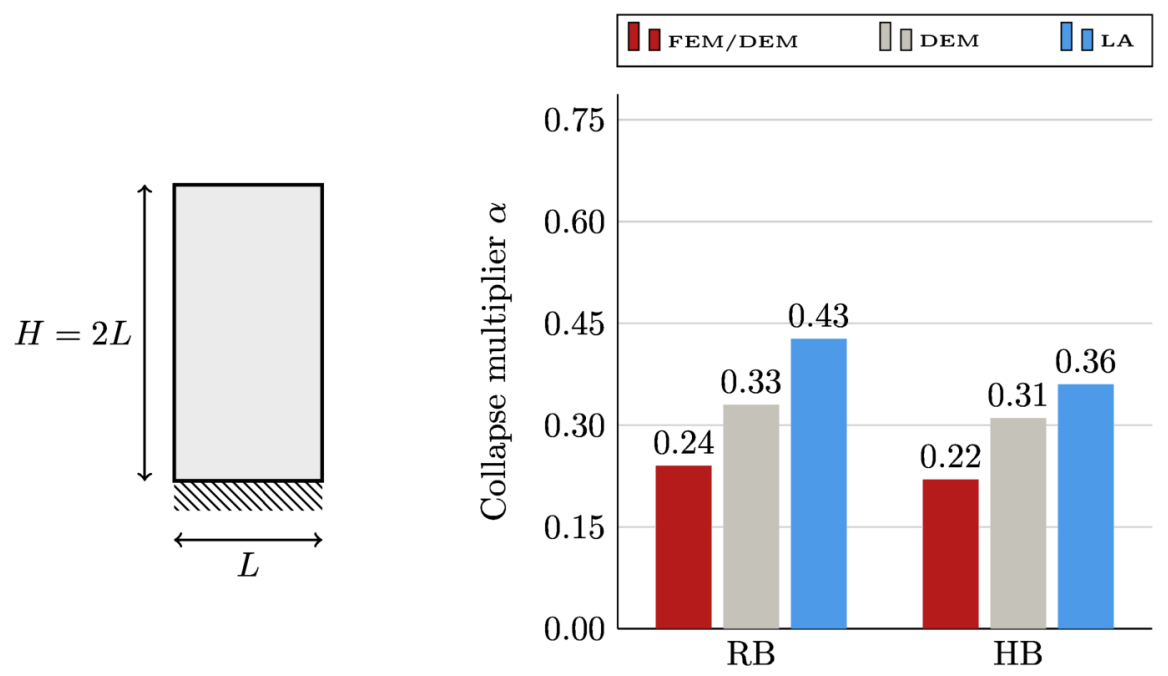

Figure 7: Case 3: Collapse multiplier for the analysed three approaches in the case $b / a=4 / 1(\mathrm{RB})$ and $b / a=2 / 1$ (HB)

[3] G. Alfano and E. Sacco. Combining interface damage and friction in a cohesive-zone model. International Journal for Numerical Methods in Engineering, 68(5):542-582, 2006.

[4] C. Baggio and P. Trovalusci. Limit analysis for no-tension and frictional three-dimensional discrete systems. Mechanics of Structures and Machines, 26(3):287-304, 1998.

[5] C. Baggio and P. Trovalusci. Collapse behaviour of three-dimensional brick-block systems using non-linear programming. Structural Engineering and Mechanics, 10(2):181-195, 2000

[6] D. Baraldi and A. Cecchi. Discrete approaches for the nonlinear analysis of in plane loaded masonry walls: Molecular dynamic and static algorithm solutions. European Journal of Mechanics, A/Solids, 57:165-177, 2016.

[7] D. Baraldi, E. Reccia, and A. Cecchi. DEM \& FEM/DEM models for laterally loaded masonry walls. In Eccomas Proceedia ID: 3528, Conference Proceeding ID: 715, pages 2144-2157, 2015.

[8] D. Baraldi, E. Reccia, and A. Cecchi. In plane loaded masonry walls: DEM and FEM/DEM models. A critical review. Meccanica, 53(7):1613-1628, 2018.

[9] D. Capecchi, G. Ruta, and P. Trovalusci. Voigt and Poincaré's mechanistic-energetic approaches to linear elasticity and suggestions for multiscale modelling. Archive of Applied Mechanics, 81(11):1573-1584, 2011.

[10] C. Casalegno, A. Cecchi, E. Reccia, and S. Russo. Heterogeneous and continuous models: Comparative analysis of masonry wall subjected to differential settlements. Composites: Mechanics, Computations, Applications, 4(3):187-207, 2013.

[11] L. Cascini, R. Gagliardo, and F. Portioli. Liablock_3d: A software tool for collapse mechanism analysis of historic masonry structures. International Journal of Architectural Heritage, 0(0):1-20, 2018. 
[12] A. Cecchi and K. Sab. A comparison between a 3D discrete model and two homogenised plate models for periodic elastic brickwork. International Journal of Solids and Structures, 41(9-10):2259-2276, 2004.

[13] G. Del Piero. Constitutive equation and compatibility of the external loads for linear elastic masonry-like materials. Meccanica, 24(3):150-162, 1989.

[14] D. C. Drucker. Coulomb friction, plasticity, and limit loads. Technical report, Brown Univ Providence RI DIV of Applied Mathematics, 1953.

[15] N. Fantuzzi, P. Trovalusci, and S. Dharasura. Mechanical behavior of anisotropic composite materials as micropolar continua. Frontiers in Materials, 6, 2019.

[16] F. Greco, L. Leonetti, R. Luciano, and P. Nevone Blasi. An adaptive multiscale strategy for the damage analysis of masonry modeled as a composite material. Composite Structures, 153:972-988, 2016.

[17] F. Greco, L. Leonetti, R. Luciano, and P. Trovalusci. Multiscale failure analysis of periodic masonry structures with traditional and fiber-reinforced mortar joints. Composites Part B: Engineering, 118:75-95, 2017.

[18] J. Lemos. Discrete element modeling of masonry structures. International Journal of Architectural Heritage, 1(2):190-213, 2007.

[19] L. Leonetti, N. Fantuzzi, P. Trovalusci, and F. Tornabene. Scale effects in orthotropic composite assemblies as micropolar continua: A comparison between weakand strongform finite element solutions. Materials, 12(5), 2019.

[20] L. Leonetti, F. Greco, P. Trovalusci, R. Luciano, and R. Masiani. A multiscale damage analysis of periodic composites using a couple-stress/Cauchy multidomain model: Application to masonry structures. Composites Part B: Engineering, 141:50-59, 2018.

[21] D. Liberatore, D. Addessi, and M. Sangirardi. A nonlinear macroelement formulation for the seismic analysis of masonry buildings. In Eccomas Proceedia ID: 5575, Conference Proceeding ID: 17126, volume 1, pages 2395-2403, 2017.

[22] H. Lotfi and P. s. Shing. Interface Model Applied to Fracture of Masonry Structures. Journal of Structural Engineering-ASCE, 120, 011994.

[23] P. Lourenço and J. Rots. Multisurface interface model for analysis of masonry structures. Journal of Engineering Mechanics, 123(7):660-668, 1997.

[24] O. Mahabadi, A. Lisjak, A. Munjiza, and G. Grasselli. Y-Geo: New combined finitediscrete element numerical code for geomechanical applications. International Journal of Geomechanics, 12(6):676-688, 2012.

[25] R. Masiani and P. Trovalusci. Cosserat and Cauchy materials as continuum models of brick masonry. Meccanica, 31(4):421-432, 1996.

[26] A. Munjiza. The combined finite-discrete element method. 2004. 
[27] D. Oliveira and P. Lourenço. Implementation and validation of a constitutive model for the cyclic behaviour of interface elements. Computers and Structures, 82(17-19):1451-1461, 2004.

[28] A. Pau and P. Trovalusci. Block masonry as equivalent micropolar continua: The role of relative rotations. Acta Mechanica, 223(7):1455-1471, 2012.

[29] M. Pingaro, E. Reccia, and P. Trovalusci. Homogenization of Random Porous Materials With Low-Order Virtual Elements. ASCE-ASME Journal of Risk and Uncertainty in Engineering Systems, Part B: Mechanical Engineering, 5(3), 2019.

[30] M. Pingaro, E. Reccia, P. Trovalusci, and R. Masiani. Fast statistical homogenization procedure (FSHP) for particle random composites using virtual element method. Computational Mechanics, 64(1):197-210, 2019.

[31] F. Portioli, C. Casapulla, M. Gilbert, and L. Cascini. Limit analysis of 3d masonry block structures with non-associative frictional joints using cone programming. Computers \& Structures, 143:108 - 121, 2014.

[32] D. Radenkovic. Théorèmes limites pour un matériau de Coulomb á dilation non standardisée. Comptes rendus hebdomadaires des séances de l'Académie des Sciences, 252(26):4103, 1961.

[33] E. Reccia, L. Leonetti, P. Trovalusci, and A. Cecchi. A multiscale/multidomain model for the failure analysis of masonry walls: A validation with a combined FEM/DEM approach. International Journal for Multiscale Computational Engineering, 16(4):325-343, 2018.

[34] R. Serpieri, M. Albarella, G. Alfano, and E. Sacco. Analysis of failure in quasi-brittle materials by $3 \mathrm{~d}$ multiplane cohesive zone models combining damage, friction and interlocking. volume 3, pages 441-449, 2017.

[35] P. Trovalusci and R. Masiani. Non-linear micropolar and classical continua for anisotropic discontinous materials. International Journal of Solids and Structures, 40(5):1281-1297, 2003.

[36] P. Trovalusci, V. Varano, and G. Rega. A generalized continuum formulation for composite microcracked materials and wave propagation in a bar. Journal of Applied Mechanics, Transactions ASME, 77(6), 2010. 